\title{
Post-Traumatic Giant Left Ventricular Pseudoaneurysm: a Multimedia Presentation
}

Danilo Tadao Wada ${ }^{1}, \mathrm{MD}$; Marcel Koenigkam-Santos ${ }^{1,2}, \mathrm{MD}, \mathrm{PhD}$; André Schmidt ${ }^{2}, \mathrm{MD}$, PhD; Alfredo José Rodrigues ${ }^{2}, \mathrm{MD}, \mathrm{PhD}$; Paulo Roberto B. Evora ${ }^{2}, \mathrm{MD}, \mathrm{PhD}$

\section{Abstract}

Traumatic left ventricular pseudoaneurysms are rare and surgical correction is the treatment of choice. In this article, it is reported a case of a myocardial stab injury with primary suture and development of a giant pseudoaneurysm, five years later, that underwent surgical repair.

Keywords: Aneurysm, False. Wounds, Stab. Heart Ventricules. Myocardium. Sutures.

\begin{tabular}{ll}
\hline Abbreviations, acronyms \& symbols \\
\hline CPB & $=$ Cardiopulmonary bypass \\
LV & $=$ Left ventricle \\
LVP & $=$ Left ventricular pseudoaneurysm \\
MRI & $=$ Magnetic resonance imaging \\
\hline
\end{tabular}

\section{INTRODUCTION}

Left ventricular pseudoaneurysms (LVP) form in the presence of a cardiac rupture contained by surrounding structures, like the pericardium or scar tissue ${ }^{[1]}$. Thus, unlikely true aneurysms, a LVP contains no endocardium or myocardium, being more propense to ruptures ${ }^{[2-4]}$. Trauma is a rare cause, given the high mortality in this scenario ${ }^{[5]}$

Because patients frequently present with nonspecific symptoms, a high index of suspicion is needed to make the diagnosis. Whereas electrocardiography and chest X-ray abnormalities are almost always present, they are also usually nonspecific ${ }^{[1]}$.

This is the report of the investigation and treatment of a case of penetrating thoracic trauma by stab with initial surgical repair evolving to a giant LVP after five years of indolent evolution.

'Centro de Ciências das Imagens e Física Médica, Hospital das Clínicas da Faculdade de Medicina de Ribeirão Preto - Universidade de São Paulo (HCFMRPUSP), Ribeirão Preto, SP, Brazil.

${ }^{2}$ Faculdade de Medicina de Ribeirão Preto - Universidade de São Paulo (FMRPUSP), Ribeirão Preto, SP, Brazil.

This study was carried out at the Centro de Ciências das Imagens e Física Médica, Hospital das Clínicas da Faculdade de Medicina de Ribeirão Preto - Universidade de São Paulo (HCFMRP-USP), Ribeirão Preto, SP, Brazil.

\section{PATIENT CHARACTERIZATION}

\section{Clinical Data}

A 34-year-old female, inmate, reported intermittent episodes of exercise-related chest pain and mild dyspnea. The patient reported a traumatic stab injury in the chest five years before that underwent surgery with suture of pulmonary and myocardial lacerations.

In the physical examination, patient had blood pressure and heart rate between normal values with a regular two-stroke heart rhythm. Continuous 4+/6+ murmur with fremitus and cervical irradiation were noted.

\section{Radiography}

Mediastinal mass with left cardiac silhouette lost and opacification of the retrosternal space is shown (Figure 1).

\section{Electrocardiography}

Sinusal rhythm with signs of left ventricular overload (Figure 1).

\section{Transthoracic Echocardiography with Doppler Evaluation}

Moderate dilatation of left ventricle (LV) with a large pseudoaneurysm in the mid-anterior wall. Severe ejection

\section{Correspondence Address:}

Danilo Tadao Wada

(iD) http://orcid.org/0000-0002-6433-4849

Hospital das Clínicas de Ribeirão Preto, Centro de Ciências das Imagens e Física Médica

Avenida Bandeirantes, 3900 - Vila Monte Alegre - Ribeirão Preto, SP, Brazil

Zip Code: 14049-900

E-mail:dwada@hcrp.usp.br 
fraction impairment (31\%) with mid-anterior and apical anterior hypokinesis (Video 1). Bidirectional flow is seen between the LV and the pseudoaneurysm cavity (Video 2).

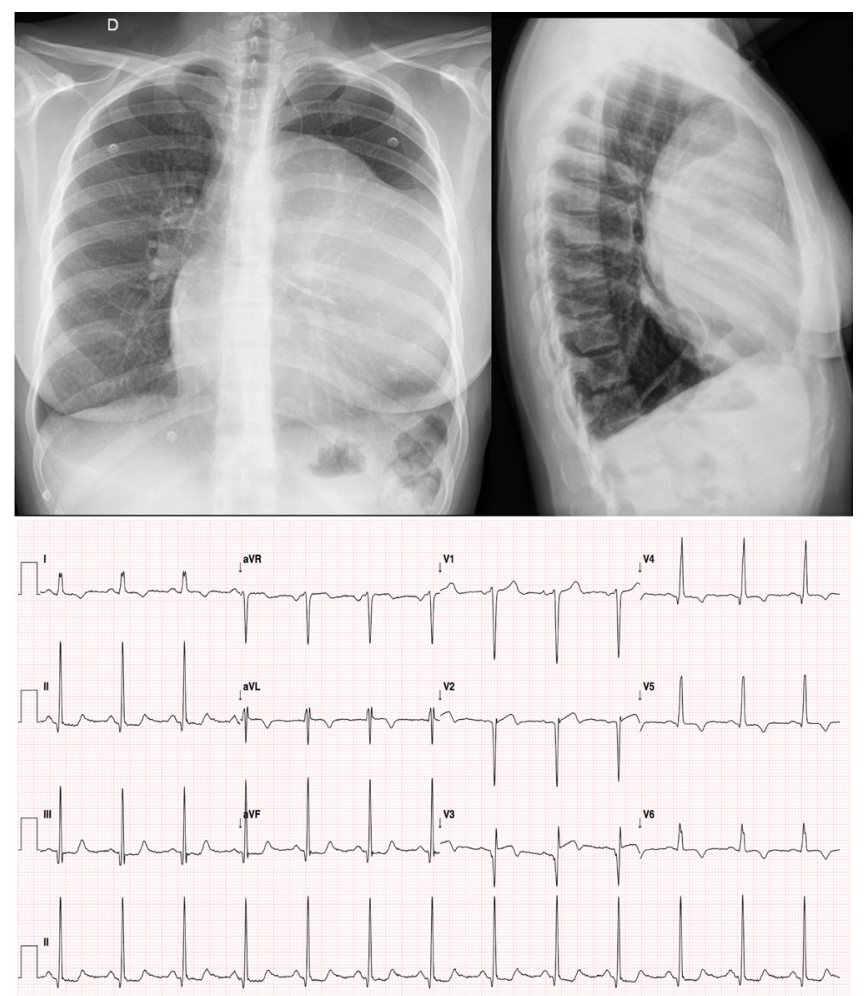

Fig. 1 - Frontal (upper left) and profile (upper right) chest radiographies and electrocardiography (bottom) showing sinusal rhythm with signs of left ventricular overload.

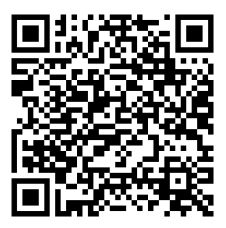

Video 1 - Transthoracic echocardiography: left ventricular pseudoaneurysm neck and anterior wall hypokinesis.

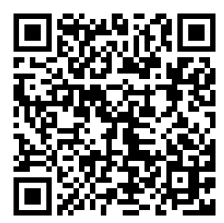

Video 2 - Transthoracic echocardiography, Doppler evaluation: bidirectional flow between the left ventricle and the left ventricular pseudoaneurysm cavity.

\section{Cardiac Magnetic Resonance Imaging}

Magnetic resonance imaging (MRI) was able to precisely evaluate the focal disruption of the left ventricular mid-anterior wall (Figure 2 and Video 3), also allowing visualization of the entire LVP, helping to exclude thrombus in it. Signs of myocardial ischemic disease were also depicted (not shown in the figures).

\section{Cardiac Catheterism}

Large pseudoaneurysm cavity with complete obstruction of mid segment of left anterior descending coronary artery at the level of LVP neck (Figure 3, Video 4, and Video 5).

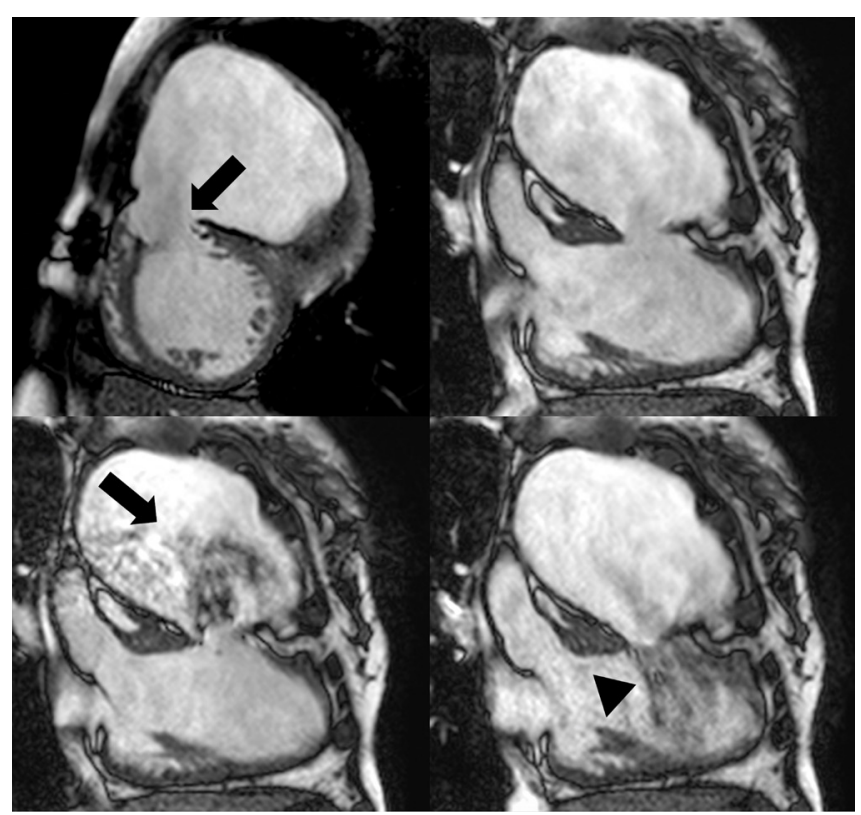

Fig. 2 - Left ventricular short-axis cinemagnetic resonance image (upper left) showing the mid-anterior wall disruption point (arrow). Oblique left ventricular long-axis cine images during end diastole (upper right), systole (bottom left), and mid diastole (bottom right). Turbulent flow is depicted from the left ventricle to the pseudoaneurysm in the systole (arrow), with reflow during diastole (arrowhead).

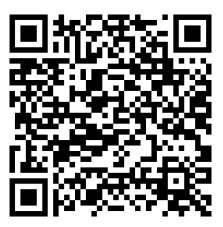

Video 3 - Magnetic resonance imaging, left ventricular shortaxis cine imaging: left ventricular anterior wall disruption and left ventricular pseudoaneurysm. 


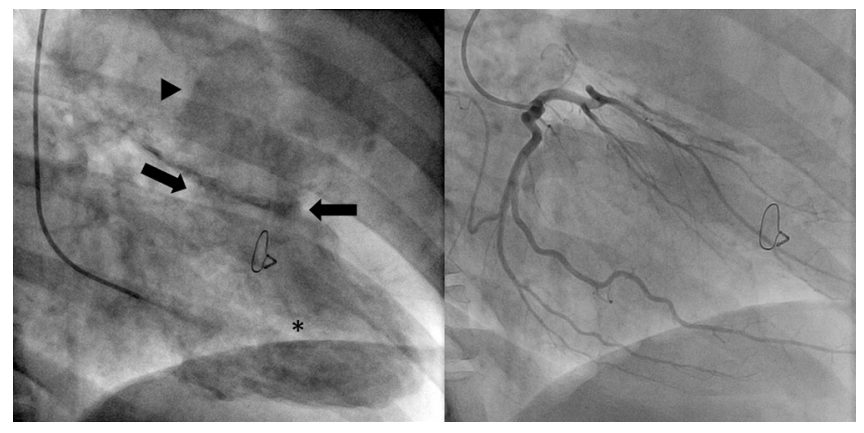

Fig. 3 - Cardiac ventriculography (left) showing the neck of the pseudoaneurysm (arrows) in the left ventricular $\left(^{*}\right)$ anterior wall with turbulent flow in its cavity (arrowhead). Left coronary catheterism is also shown (right).

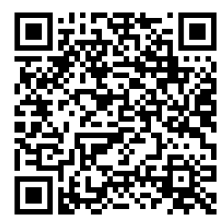

Video 4 - Magnetic resonance imaging, left ventricular long-axis cine imaging: bidirectional turbulent flow.

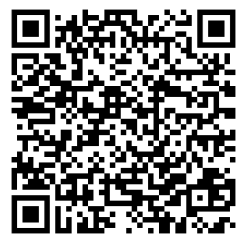

Video 5 - Cardiac ventriculography: left ventricle and left ventricular pseudoaneurysm.

\section{DESCRIPTION OF THE TECHNIQUE EMPLOYED}

The patient underwent surgical correction of the pseudoaneurysm by direct suture with good evolution. Medium sternotomy was performed after femoro-femoral cardiopulmonary bypass (CPB) had been established. The patient was cooled down to $28^{\circ} \mathrm{C}$. The ascending aorta was not cross-clamped. The fibrous wall of the pseudoaneurysm was identified and its medial surface (contiguous to the anterior mediastinum) was widely opened during a short period of circulatory arrest and ventricular fibrillation, in order to depressurize the LV and the pseudoaneurysm and to prevent air embolism. The left ventricular wound was identified $\left(3.5 \mathrm{~cm}{ }^{\prime} 5 \mathrm{~cm}\right)$ and the $\mathrm{CPB}$ restarted. The wound was closed using a bovine pericardial patch sutured to its margin with horizontal mattress stiches (Ethibond 2.0, Ethicon ${ }^{\oplus}$ ) during ventricular fibrillation. Maneuvers to remove air from the LV were performed before tying the last stich. Besides a mediastinal drain, a suction drain was positioned inside of the pseudoaneurysm cavity (left open to the anterior mediastinum) and the chest was closed as usual. The suction drain was removed few days later, when the serosanguineous drainage was $<100 \mathrm{ml} / 24 \mathrm{~h}$.

\section{Clinical Follow-up}

Another cardiac MRI was made six months latter showing a minimal residual cavity without signs of complication. After surgery, the patient had a good postoperative evolution without complications, being discharged from hospital after 11 days. She is at clinical and imaging follow-up, with a two-year evolution, without worsening of symptoms.

\section{DISCUSSION}

The incidence of LVP is low and most of the cases are related to acute myocardial infarction, cardiac surgery, and trauma. LVP have become a rare complication of acute myocardial infarction, occurring in approximately $2 \%$ of the cases or less, when thrombolytic or primary percutaneous intervention can be performed $^{[6,7,8]}$.

The natural history of surgically treated and untreated LVP is not clearly defined ${ }^{[9]}$ and data to guide the treatment are scarce $^{[10]}$. Surgical repair is the recommended treatment, given the pseudoaneurysms' propensity for life-threatening complications, such as cardiac tamponade and shock. Untreated pseudoaneurysms have a $30 \%$ to $45 \%$ risk of rupture and the surgical repair of posttraumatic LVP has a reported mortality of $>7 \%$.

Is this article, it is reported an unusual case of post-traumatic giant LVP with an indolent evolution, although all the potential risks of rupture.

\section{No financial support. \\ No conflict of interest.}

\section{Authors' roles \& responsibilities}

DTW Drafting the work or revising it critically for important intellectual content; final approval of the version to be published

MKS Drafting the work or revising it critically for important intellectual content; final approval of the version to be published

AS Drafting the work or revising it critically for important intellectual content; final approval of the version to be published

AJR Drafting the work or revising it critically for important intellectual content; final approval of the version to be published

PRBE Substantial contributions to the conception or design of the work; drafting the work or revising it critically for important intellectual content; final approval of the version to be published 


\section{REFERENCES}

1. Frances C, Romero A, Grady D. Left ventricular pseudoaneurysm. J Am Coll Cardiol. 1998;32(3):557-61. doi:10.1016/s0735-1097(98)00290-3.

2. Vlodaver Z, Coe JI, Edwards JE. True and false left ventricular aneurysms. Propensity for the altter to rupture. Circulation. 1975;51(3):567-72. doi:10.1161/01.CIR.51.3.567.

3. Zoffoli G, Mangino D, Venturini A, Terrini A, Asta A, Zanchettin C, et al. Diagnosing left ventricular aneurysm from pseudo-aneurysm: a case report and a review in literature. J Cardiothorac Surg. 2009;4(1):11. doi:10.1186/1749-8090-4-11.

4. Bisoyi S, Dash AK, Nayak D, Sahoo S, Mohapatra R. Left ventricular pseudoaneurysm versus aneurysm a diagnosis dilemma. Ann Card Anaesth. 2016;19(1):169-72. doi:10.4103/0971-9784.173042.

5. Mulder DG. Stab Wound Of The Heart. Ann Surg. 1964;160:287-91. doi:10.1097/00000658-196408000-00017.
6. Hsu YH, Chiu IS, Chien CT. Left ventricular pseudoaneurysm diagnosed by magnetic resonance imaging in a nine-year-old boy. Pediatr Cardiol. 1993;14(3):187-90. doi:10.1007/BF00795654.

7. Bhardwaj R, Sondhi S, Mehta A. Unruptured giant left ventricular pseudoaneurysm after silent myocardial infarction. BMJ Case Rep. 2018; pii: bcr-2018-225812. doi:10.1136/bcr-2018-225812.

8. Irazusta FJ, Ramirez U, Caro-Codon J, Refoyo E, Garrido D, Pinilla I, et al. Extensive chest wall destruction secondary to a large ventricle pseudoaneurysm: a surgical challenge. Ann Thorac Surg. 2017;103(3):e227-9. doi:10.1016/j.athoracsur.2016.09.007.

9. Hulten EA, Blankstein R. Pseudoaneurysms of the heart. Circulation. 2012;125(15):1920-5. doi:10.1161/CIRCULATIONAHA.111.043984.

10. Gigase A, Spapen J, Penicka M, Van Camp G. Giant pseudoaneurysm of the left ventricle. Int J Cardiovasc Imaging. 2019; 35(6):1161-2. doi:10.1007/s10554-019-01558-0. 